\title{
Risk Assessment for Breast Cancer Development and Its Clinical Impact on Screening Performance in Iranian Women
}

This article was published in the following Dove Press journal: Cancer Management and Research

\author{
Maryam Nikpour' \\ Karimollah Hajian-Tilaki ${ }^{2}$ \\ Afsaneh Bakhtiari $\mathbb{D}^{3}$ \\ 'Student Research Committee, Health \\ Research Institute, Babol University of \\ Medical Sciences, Babol, Iran; \\ ${ }^{2}$ Department of Biostatistics and \\ Epidemiology, School of Medicine, Babol \\ University of Medical Sciences, Babol, \\ Iran; ${ }^{3}$ Department of Midwifery, School \\ of Medicine, Babol University of Medical \\ Sciences, Babol, Iran
}

Introduction: The aim of this study is to estimate the objective and subjective risk and to examine their associations with three forms of breast cancer screening.

Methods: This cross-sectional study was conducted with a sample of 800 women aged 35-85 years from the community setting and outpatient clinic in Babol, the north of Iran. The demographic, socio-economic characteristics and the risk factor profiles were collected through inperson interview. The health belief model (HBM) and visual analog scales were used to assess the women's perceived risk of breast cancer. The practice of women regarding breast selfexamination (BSE), breast clinical examination (BCE), and mammography were measured. We used the Gail model in estimating 5-year and lifetime risk. The logistic regression model was applied to determine the relationship of calculated and perceived risk on screening behaviors.

Results: The mean of estimated 5-year and lifetime risk were $0.89 \pm 0.89$ and 8.87 \pm 3.84 percent respectively while the perceived personal risk on visual scale perception was much greater than the calculated risk. The high 5-year calculated risk was a predictor of mammography practice but not BSE and BCE; however, after adjusting the subscales of HBM and socio-demographic characteristics, its effect remained significant (adjusted $\mathrm{OR}=1.97(95 \% \mathrm{CI}: 1.02-3.08))$. The perceived risk from HBM in particular self-efficacy $(p=0.001)$ remained positively significant on all forms of screening practice.

Conclusion: While the perceived risk from HBM scale was meaningful in screening performance, the calculated risk from the Gail model had a clinical impact on mammography behaviors independent of HBM scales.

Keywords: breast cancer risk, the Gail model, the health belief model, perceived risk, the estimated risk, screening behaviors

\section{Introduction}

Breast cancer is the most common malignancy in women, causing about $30 \%$ of all cancer incidences and $20 \%$ of cancer death in women. ${ }^{1-3}$ Breast cancer is also the most common cancer among Iranian women and the mean age of its incidence is lower about a decade compared with western countries. ${ }^{4,5}$ An increasing trend of breast cancer mortality has been observed worldwide. ${ }^{6}$ An updated strategy must focus on prevention in both developing and industrial countries. To establish a preventive strategy, it is required, initially, to precisely assess the risk of breast cancer development in a population.

Several models have been adopted to assess the perceived risk on the performance of breast cancer screening in health behavior theory, especially the health belief
Correspondence: Karimollah Hajian-Tilaki Department of Biostatistics and Epidemiology, School of Medicine, Babol University of Medical Sciences, Babol, Iran Email drhajian@yahoo.com 
model (HBM) ${ }^{7,8}$ Another form of subjective assessment was applied using a visual analog scale (VAS). However, a popular objective risk assessment model was adopted by the Gail model estimating individual risk based on risk factor profiles. The most famous of which is called the modified Gail model. ${ }^{9,10}$ This model combines the multiple risk factors into a comprehensive and single risk score that is crucially important in clinical decision-making. It predicts the 5-year and lifetime individual risk of the development of breast cancer in women of 35 years of age or older. $^{10}$

Despite changing in lifestyles of women such as diet, physical activity, obesity and reproductive behaviors in the north of Iran, in the two recent decades, ${ }^{5,11,12}$ the data of 5-year and lifetime risk of breast cancer development are sparse in this region. Few pieces of evidence from previous studies, however, showed a low screening performance (breast self-examination (BSE), breast clinical examination (BCE) and mammography) in women, ${ }^{13,14}$ but high prevalence of obesity and low level of physical activity were reported among women in this population. ${ }^{12,15}$ Few studies, however, evaluated the risk of breast cancer in Iranian women ${ }^{16-19}$ but none of them reported its independent clinical impact on breast cancer screening performance and the awareness of women about their risk. Meanwhile, there is no data on 5-year/lifetime breast cancer risk in the population of the north of Iran and no evidence exists whether the calculated risk is as predictor of performance of women on BSC, BCE and mammography practice independently from the perceived risk of HBM scale. The clinical implication of such an association is that an indicator of women's knowledge of running a high risk could inform them in early detection with screening practice from a clinical perspective. ${ }^{20}$ To the best of our knowledge, it can be novel research on Asian women to examine the objective risk measure as a predictor of screening performance independently from the perceived risk of HBM scale. From the public health view, the quantitative risk assessment is particularly interesting in estimating the high-risk women, financial costs and resources for early detection with advanced magnetic resonance imaging techniques and prophylactic therapeutics to make clinical decisions. Thus, the objective of this study was to assess the 5-year and lifetime risk of developing breast cancer in women as compared to the perceived risk by the HBM on screening performance from a clinical perspective.

\section{Methods and Subjects}

\section{Study Design and Subjects}

This cross-sectional study was conducted in Babol, north of Iran, in 2018. Participants were 800 women of the urban population under the coverage of health centers and specialist outpatient clinics of the affiliated hospitals of Babol University of medical sciences. The sample size can detect a standardized effect size of 0.2 in estimated risk score on screening performance with $80 \%$ power at a $95 \%$ confidence level. A cluster sampling technique was applied to select 12 random areas of the urban population, under the coverage of urban health centers and also the three outpatient clinics of teaching hospitals. Then, within each cluster of health centers, 50 women aged 35-85 years were recruited consecutively from the center of each random cluster in a health survey at home visit. Also, 200 additional participants were recruited at outpatient clinics of three major teaching hospitals consecutively. We excluded women with a history of a confirmed diagnosis of invasive breast cancer and also those who already had the diagnosis of either ductal or lobular breast carcinoma in situ. About $90 \%$ of the eligible subjects who met the inclusion and exclusion criteria had given written consent to participate in the study and the study protocol was approved by the Ethical Committee of the National Institute of Medical Research Development (NIMAD), Tehran, Iran.

\section{Instruments and Measurements}

All data were collected through face-to-face interviews with participants using questionnaires by trained nurses. Instruments consisted of three questionnaires. The first measured the demographic, socio-economic characteristics and the risk factor profiles in particular. We collected data on age, age at the first menstrual period, age at the first live birth, history of breast cancer among first-degree female relatives (mother, sisters, and daughters), and the number of previous breast biopsies and the presence of atypical hyperplasia in previous biopsies. We also collected data on the level of education, occupational status of women, family income, and menopausal status. The second instrument was a validated Champion's health belief model scale (CHBMS) for breast cancer screening that consists of 6 subscales of health belief including perceived susceptibility (5 items), perceived seriousness (7 items), perceived barriers (5 items), perceived confidence/ self-efficacy (11 items) and perceived health motivation (6 items). ${ }^{7,8}$ All items in different domains were rated on 
a five-point likert scale from 1 (definitely disagree) to 5 (definitely agree). The highest score indicates the positive belief in all subscales except for barriers that the higher shows the negative belief. The reliability coefficients of the Persian version of this instrument as calculated by Cronbach's $\alpha$ ranged from 0.83 to 0.96 depending on subscales used in our previous reports. ${ }^{14}$ We also estimated this reliability coefficient in our data, which ranged from 0.76 to 0.97 in different subscales. Additionally, we assessed the women's perception of 5-year and lifetime breast cancer risk on the visual analog scale (VAS) from 0 to 100 . The third questionnaire measured the practice of women regarding breast examination, more specifically on BSE, BCE, and mammography. The knowledge and the frequency of each were asked, as well as whether the participants participated in an educational program by the health care provider or other sources, particularly in BSE. The knowledge and the frequency of BSC practice were answered with 5 choices (I do not know at all; I know but I never applied it; I apply it whenever it comes up to my mind; once a month; other). The frequency of performing BCE was recorded with 5 choices (never; yes; if I have any complaint; once a year; once in two years; other). Finally, the knowledge of mammography and the frequency of its performance was recorded with 5 choices (I do not know; yes I know but I never underwent it; once a year; every two years; other).

\section{Breast Cancer Risk Assessment Tool}

We performed the modified Gail model in estimating the 5-year risk and lifetime risk of breast cancer development for each participant using an online computerized program of breast cancer risk assessment tools. This interactive tool was designed by the US National Cancer Institute (NCI) to estimate women's risk of developing breast cancer based on the Gail model. This model was built based on data from the Breast Cancer Detection and Demonstration Project of mammography screening involving over 280,000 US women. ${ }^{10}$ The Gail model uses women's personal medical history, familial history, and reproductive history. More specifically, it considers the age of women, the age at the first menstrual period, the age at the first live birth, and the number of women's first degree relatives (mother, sisters, and daughters) with a confirmed diagnosis of breast cancer. Particularly, it takes into account the number of previous biopsies and the presence of any atypical hyperplasia on any of biopsies. This model has been validated in breast cancer prediction in different populations and is generally accurate in risk projection. ${ }^{21-23}$ However, some overestimation of the likelihood of risk may occur in a specific subgroup (e.g. younger women who are not a candidate for regular mammography).

\section{Statistical Analysis}

We used the SPSS software version 18.0 in data analysis. The descriptive data were presented as the mean (SD) of 5 -years and lifetime risk of developing breast cancer. In bivariate analysis, we performed an analysis of variance by running the Kruskal-Wallis test to compare the estimated 5-year risk and lifetime risk with demographic and clinical characteristics. Also, the mean of calculated/estimated risk and perceived risk in different dimensions of HBM were compared between those who regularly performed screening procedures versus not using the Wilcoxon rank test of the two independent samples for non-normal data and also ranked data. Furthermore, the Spearman correlation coefficients between risk scores and health belief scores in different subscales were estimated and tested. Additionally, the 5-year risk score was categorized at the cutoff value of $1.66 \%$ that was proposed by Gail; those with a risk score of more than $1.66 \%$ were considered as the high-risk group and those with the score of less than or equal to $1.66 \%$ as a lowrisk group. We used the logistic regression model to estimate the odds ratio of high-risk group versus low risk on the performance of regular BSE, BCE, and Mammography. In the logistic regression model, the outcomes of interest defined as performing regular BSE (once per month) versus do not know how to perform $\mathrm{BSE}$ or not perform BSE regularly; the individuals who regularly attended clinics (i.e. once a year) for $\mathrm{BCE}$ and women who have performed mammography once a year or every two years as outcome of interest. The logistic regression model was performed. The estimated odds ratio (OR) was adjusted by the score of different subscales of the health belief model, age groups, level of education, and income level. The 95\% confidence interval for OR was calculated. In the analysis, all statistical tests were run two-sided and $\mathrm{p}<0.05$ was considered as significant level.

\section{Results}

A total of 800 women were recruited in the study with the mean age (SD) of $47.63 \pm 10.46$ years. The mean age of the first experience of menstrual and the age at first live birth were $13.09 \pm 1.64$ and $21.8 \pm 4.45$, respectively. The characteristic of the study population and the average of 5-year and lifetime risk are shown in Table 1. The mean of 
Table I Demographic and Clinical Characteristics and the Estimated 5- Year and Lifetime Risk

\begin{tabular}{|c|c|c|c|c|c|}
\hline Characteristics & $n(\%)$ & $\begin{array}{l}\text { Estimated 5- Year } \\
\text { Risk Mean } \pm \text { SD (\%) }\end{array}$ & P-value ${ }^{k}$ & $\begin{array}{l}\text { Estimated Lifetime } \\
\text { Risk Mean } \pm S D(\%)\end{array}$ & p-value ${ }^{k}$ \\
\hline $\begin{array}{l}\text { Age group (year) } \\
35-49 \\
50-64 \\
65-85\end{array}$ & $\begin{array}{l}492(61.5) \\
251(31.4) \\
57(7.1)\end{array}$ & $\begin{array}{l}0.59 \pm 0.34 \\
1.22 \pm 0.76 \\
1.98 \pm 2.29\end{array}$ & 0.001 & $\begin{array}{l}9.81 \pm 3.32 \\
7.79 \pm 3.61 \\
5.58 \pm 5.92\end{array}$ & 0.001 \\
\hline $\begin{array}{l}\text { Ist Menstrual age (year) } \\
7-1 \mid \\
\mid 2-13 \\
\geq 14\end{array}$ & $\begin{array}{l}119(15.1) \\
364(46.3) \\
303(38.5)\end{array}$ & $\begin{array}{l}0.91 \pm 0.08 \\
1.06 \pm 0.05 \\
0.63 \pm 0.04\end{array}$ & 0.14 & $\begin{array}{l}9.86 \pm 3.97 \\
9.16 \pm 4.38 \\
8.30 \pm 2.99\end{array}$ & 0.001 \\
\hline $\begin{array}{l}\text { Age at Ist birth(year) } \\
<20 \text { y } \\
20-24 \\
25-29 \\
\geq 30\end{array}$ & $\begin{array}{l}249(33.2) \\
317(42.3) \\
14 \mid(18.8) \\
43(5.7)\end{array}$ & $\begin{array}{l}0.86 \pm 1.25 \\
0.86 \pm 0.66 \\
1.02 \pm 0.86 \\
0.99 \pm 0.59\end{array}$ & 0.27 & $\begin{array}{l}7.22 \pm 3.85 \\
8.38 \pm 2.96 \\
10.86 \pm 4.09 \\
12.81 \pm 3.01\end{array}$ & 0.001 \\
\hline $\begin{array}{l}\text { Age at marriage (year) } \\
\leq 20 \\
20-24 \\
25-29 \\
\geq 30\end{array}$ & $\begin{array}{l}437(56.5) \\
245(31.7) \\
71(9.2) \\
21(2.7)\end{array}$ & $\begin{array}{l}0.87 \pm 1.03 \\
0.90 \pm 0.65 \\
1.05 \pm 0.85 \\
0.92 \pm 0.50\end{array}$ & 0.47 & $\begin{array}{l}7.83 \pm 3.52 \\
9.36 \pm 3.44 \\
11.076 \pm 5.13 \\
12.92 \pm 2.95\end{array}$ & 0.001 \\
\hline $\begin{array}{l}\text { No of Ist degree with breast cancer } \\
\text { None } \\
\text { I } \\
>1\end{array}$ & $\begin{array}{l}744(93.0) \\
52(6.5) \\
4(0.5)\end{array}$ & $\begin{array}{l}0.79 \pm 0.44 \\
1.92 \pm 1.62 \\
6.2 \pm 7.71\end{array}$ & 0.001 & $\begin{array}{l}8.37 \pm 2.79 \\
14.23 \pm 6.22 \\
33.00 \pm 8.55\end{array}$ & 0.001 \\
\hline $\begin{array}{l}\text { No of biopsy } \\
\text { None } \\
1 \\
>1\end{array}$ & $\begin{array}{l}742(92.8) \\
45(5.6) \\
13(1.6)\end{array}$ & $\begin{array}{l}0.82 \pm 0.54 \\
1.69 \pm 2.73 \\
2.03 \pm 1.77\end{array}$ & 0.001 & $\begin{array}{l}8.56 \pm 0.11 \\
12.59 \pm 8.03 \\
13.67 \pm 8.13\end{array}$ & 0.001 \\
\hline $\begin{array}{l}\text { Dysplasia } \\
\text { None/not applicable } \\
\text { Present }\end{array}$ & $\begin{array}{l}788(98.5) \\
12(1.5)\end{array}$ & $\begin{array}{l}0.85 \pm 0.58 \\
3.76 \pm 4.97\end{array}$ & 0.001 & $\begin{array}{l}8.66 \pm 3.28 \\
25.05 \pm 9.97\end{array}$ & 0.001 \\
\hline $\begin{array}{l}\text { Educational level } \\
\text { Illiterate } \\
\text { Primary } \\
\text { High school } \\
\text { University level }\end{array}$ & $\begin{array}{l}78(9.8) \\
154(19.3) \\
396(49.1) \\
175(21.9)\end{array}$ & $\begin{array}{l}1.28 \pm 1.08 \\
0.98 \pm 0.48 \\
0.80 \pm 0.64 \\
0.83 \pm 1.38\end{array}$ & 0.001 & $\begin{array}{l}6.69 \pm 3.46 \\
7.62 \pm 2.93 \\
9.09 \pm 3.50 \\
10.46 \pm 4.87\end{array}$ & 0.001 \\
\hline $\begin{array}{l}\text { Marital status } \\
\text { Single } \\
\text { Married } \\
\text { Divorced } \\
\text { Widow }\end{array}$ & $\begin{array}{l}53(6.6) \\
679(84.9) \\
29(3.6) \\
39(4.9)\end{array}$ & $\begin{array}{l}0.83 \pm 0.60 \\
0.94 \pm 0.04 \\
0.63 \pm 0.41 \\
1.19 \pm 0.52\end{array}$ & 0.06 & $\begin{array}{l}9.24 \pm 2.69 \\
8.95 \pm 3.97 \\
10.03 \pm 3.93 \\
6.23 \pm 2.11\end{array}$ & 0.001 \\
\hline $\begin{array}{l}\text { Occupation } \\
\text { Housewife } \\
\text { Employee } \\
\text { Retired }\end{array}$ & $\begin{array}{l}593(74.1) \\
175(21.9) \\
32(4.0)\end{array}$ & $\begin{array}{l}0.88 \pm 0.69 \\
0.70 \pm 0.43 \\
2.09 \pm 2.90\end{array}$ & 0.001 & $\begin{array}{l}8.65 \pm 3.64 \\
9.67 \pm 3.60 \\
8.65 \pm 7.45\end{array}$ & 0.009 \\
\hline $\begin{array}{l}\text { Fertility status } \\
\text { Reproductive age } \\
\text { Menopause }\end{array}$ & $\begin{array}{l}511(64.0) \\
287(36.0)\end{array}$ & $\begin{array}{l}0.65 \pm 0.4 \mid \\
1.31 \pm \mid .28\end{array}$ & 0.001 & $\begin{array}{l}9.45 \pm 3.39 \\
7.88 \pm 4.44\end{array}$ & 0.001 \\
\hline
\end{tabular}

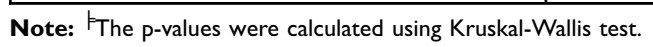


overall estimated 5-year risk and lifetime risk were 0.89 \pm 0.89 and $8.87 \pm 3.84$ percent respectively, while the corresponding value for subjectively perceived risk on VAS was much greater than the calculated risk $(9.19 \pm 16.1$ and 14.87 \pm 20.79 percent respectively). Additionally, about 61 $(7.6 \%)$ women had the calculated 5-year risk of higher than the cut-off value of $1.66 \%$ (Gail criteria) Out of 800 participants, 140 (17.5\%) participants performed BSE regularly (once per month) and 122(15.3\%) persons practiced BCE regularly (once a year) and 173 (21.6\%) used mammography annually or every two years. As demonstrated in Table 1, the estimated 5-years risk significantly increased by aging until 65 years of age and then slightly decreased $(\mathrm{p}=0.001)$, while, as expected, the lifetime risk significantly decreased over the age of $65(\mathrm{p}=0.001)$. A greater elevating of both 5-year and lifetime risk was observed by the number of first degree relatives with breast cancer, the number of biopsies and the present of dysplasia in the biopsy $(\mathrm{p}=0.001)$ and lower level of education ( $p=0.001$ ). Table 2 shows the younger women perceived slightly a higher risk on VAS than older but the difference was not significant. Among the subscales of HBM, the younger women perceived a greater susceptibility $(\mathrm{p}=0.04)$ and also benefit $(\mathrm{p}=0.03)$ than older. While the differences in other subscales were not statistically significant.

Table 3 indicated a positive correlation between subjectively perceived risk and calculated risk $(\mathrm{r}=0.08$ in 5 -year risk, $\mathrm{r}=0.13$ lifetime risk, $\mathrm{p}=0.001$ ). While the correlation between calculated risk and the perceived score of the different dimension of HBM were almost low, the correlation between the perceived score in different subscales of HBM was almost significant.

Table 2 The Perceived Risk of Breast Cancer According to Age Groups

\begin{tabular}{|c|c|c|c|}
\hline \multirow[t]{2}{*}{ Perceived Risk } & \multicolumn{2}{|l|}{ Age } & \multirow[t]{2}{*}{ p-value f $^{-1}$} \\
\hline & $\begin{array}{l}35-49 \text { y } \\
\text { Mean士SD }\end{array}$ & $\begin{array}{l}50-85 \text { y } \\
\text { Mean士SD }\end{array}$ & \\
\hline Perceived 5-year risk (VAS) (\%) & $9.73 \pm 16.54$ & $8.3 \pm 15.42$ & 0.08 \\
\hline Perceived lifetime risk (VAS) (\%) & $15.29 \pm 20.69$ & $14.20 \pm 20.95$ & 0.15 \\
\hline Perceived susceptibility score & $1.79 \pm 0.93$ & $1.65 \pm 0.82$ & 0.04 \\
\hline Perceived severity score & $2.99 \pm 1.07$ & $2.93 \pm 1.14$ & 0.32 \\
\hline Perceived benefit score & $3.45 \pm 1.09$ & $3.25 \pm 1.28$ & 0.03 \\
\hline Perceived barriers score & $|.58 \pm 0.7|$ & $1.70 \pm 0.88$ & 0.42 \\
\hline Perceived confident score & $2.62 \pm 1.07$ & $2.50 \pm 1.22$ & 0.06 \\
\hline Health motivation score & $3.48 \pm 0.79$ & $3.45 \pm 0.81$ & 0.61 \\
\hline
\end{tabular}

Note: ${ }^{\ddagger} \mathrm{p}$ - value from Wilcoxon rank test.
Table 4 compares the subjectively perceived risk on VAS, the estimated risk by the Gail model and the average scores of the various subscales of perceived risk in HBM according to the performance of BSE, BCE, and mammography. The subjectively perceived risk on the VA scale tended to be greater in women who performed both BSE and $\mathrm{BCE}$ regularly. While the 5-year calculated risk tended to be lower in the regular performance of BSE surprisingly, there was no significant difference in performing BCE. On the other hand, the estimated lifetime risk was significantly higher among those who performed BSE regularly. Among subscales of HBM, the perceived benefits, perceived confidence and perceived health motivations had a greater impact on both BSE and BCE significantly and their higher scores were associated with a better performance of breast screening $(p=0.001)$. In performing the mammography, the subjectively perceived risk had slightly higher scores than those without the experience of mammography regularly. Also, the calculated high 5-year risk is associated positively with mammography screening. The practice of mammography corresponded with a significantly greater score in perceived confident/self-efficacy $(p=0.001)$ and perceived health motivations $(p=0.02)$ and the lower score in perceived seriousness $(p=0.02)$, but there was not a significant difference in perceived barriers and benefits. Table 5 presents the results of unadjusted OR and its $95 \%$ confidence interval of estimated 5-year risk (high vs. low) and perceived score of different subscales of HBM on performing breast cancer screening. In bivariate analysis, the high estimated 5-year risk increased the odds of a better performance in mammography for 2.38 times (95\% CI: 1.37 , 4.11) but not for BSE and BCE. Again, perceived benefit and perceived confidence and perceived health motivations positively associated with screening performance (BSE, $\mathrm{BCE}$, and mammography). Surprisingly in the univariate analysis, the perceived severity score had a negative association with the performance of mammography. However, using multiple logistic regression analysis by adjusting age, level of education, income level and all subscales of HBM, as our results (Table 6) show, the association of being the high estimated 5-year risk with mammography remained significant (adjusted OR $=1.97$ (95\% CI: 1.02, 3.80). Only the perceived confidence score appeared to be significantly positively associated with all three procedures of screening performance $(p=0.001)$. However, the perceived health motivations had positively associated with $\mathrm{BCE}(\mathrm{p}=0.04)$ and the perceived susceptibility for 
Table 3 The Correlation Structure Between Estimated Risk and Perceived Risk of Health Belief Model in Different Subscales ${ }^{\vDash}$

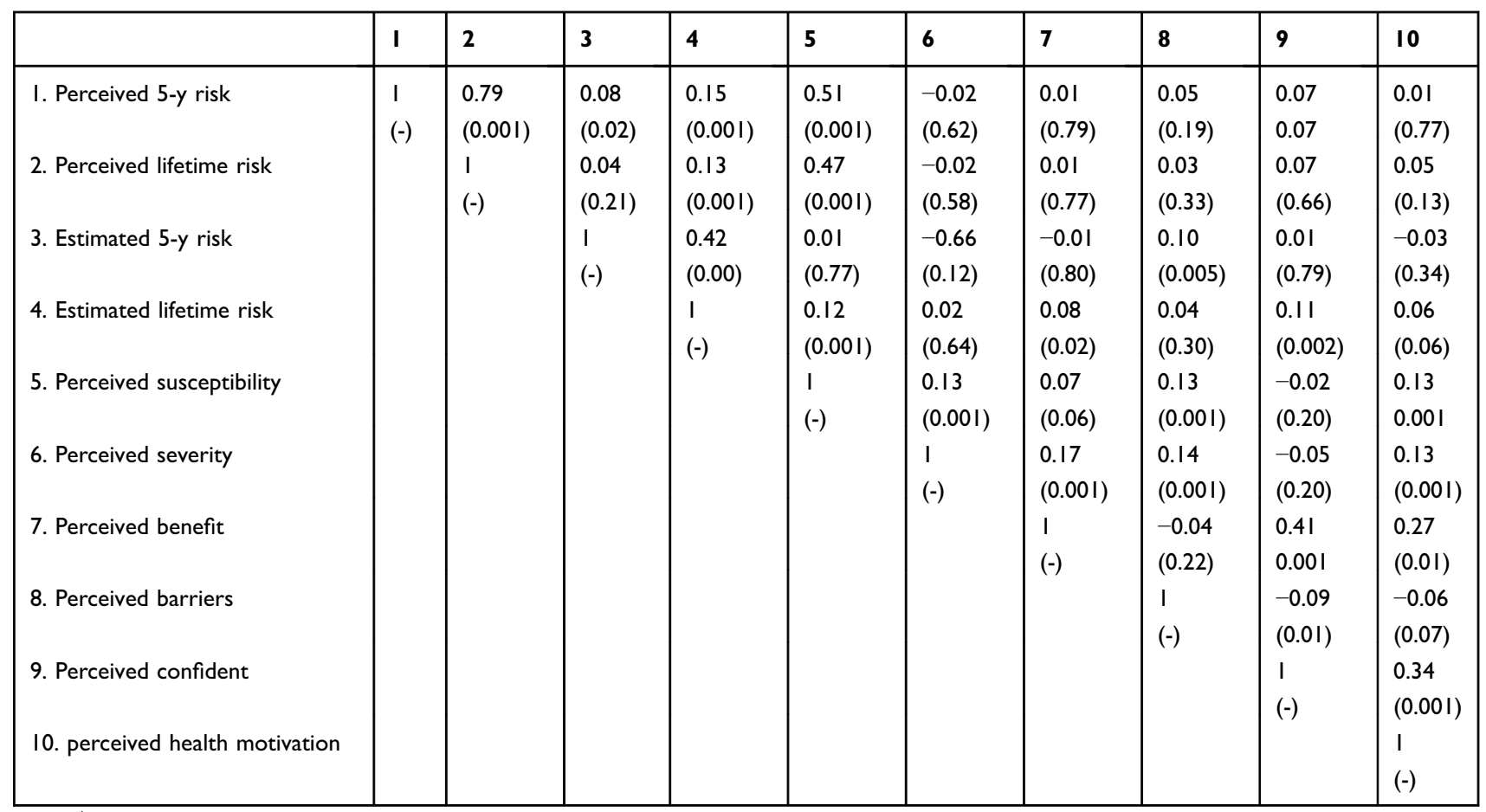

Note: FThe p-values were shown in the parenthesis.

Table 4 The Mean $( \pm S D)$ of Perceived Risk and Estimated Risk According to Performance with BSE, BCE and Mammography

\begin{tabular}{|c|c|c|c|c|c|c|c|c|c|}
\hline \multirow{2}{*}{$\begin{array}{l}\text { Perceived \& } \\
\text { Estimated Risk }\end{array}$} & \multicolumn{2}{|l|}{ BSE } & \multirow[t]{2}{*}{ p-value f $^{-1}$} & \multicolumn{2}{|l|}{ BCE } & \multirow[t]{2}{*}{ p-value ${ }^{\ddagger}$} & \multicolumn{2}{|c|}{ Mammography } & \multirow[t]{2}{*}{ p-value ${ }^{-t}$} \\
\hline & $\begin{array}{l}\text { Not } \\
\text { Performed } \\
\text { Regularly }\end{array}$ & $\begin{array}{l}\text { Performed } \\
\text { Regularly }\end{array}$ & & $\begin{array}{l}\text { Not } \\
\text { Performed } \\
\text { Regularly }\end{array}$ & $\begin{array}{l}\text { Performed } \\
\text { Regularly }\end{array}$ & & $\begin{array}{l}\text { Not } \\
\text { Performed } \\
\text { regularly }\end{array}$ & $\begin{array}{l}\text { Performed } \\
\text { Regularly }\end{array}$ & \\
\hline $\begin{array}{l}\text { Perceived 5- y risk } \\
\text { on VAS (\%) }\end{array}$ & $8.82 \pm 15.86$ & $10.93 \pm 17.25$ & 0.09 & $8.52 \pm|5.4|$ & $12.89 \pm 19.28$ & 0.06 & $8.7 \mid \pm 15.68$ & $10.94 \pm 17.56$ & 0.16 \\
\hline $\begin{array}{l}\text { Perceived lifetime } \\
\text { risk on VAS (\%) }\end{array}$ & $|4.2| \pm 20.08$ & $18.02 \pm 23.67$ & 0.09 & $13.90 \pm 19.83$ & $20.31 \pm 24.85$ & 0.02 & $13.95 \pm 19.94$ & $18.21 \pm 23.38$ & 0.03 \\
\hline $\begin{array}{l}\text { Estimated 5-year } \\
\text { risk (\%) }\end{array}$ & $0.92 \pm 3.91$ & $0.77 \pm 0.50$ & 0.03 & $0.87 \pm 0.68$ & $1.01 \pm 1.62$ & 0.64 & $0.88 \pm 0.68$ & $1.11 \pm 1.39$ & 0.001 \\
\hline $\begin{array}{l}\text { Estimated lifetime } \\
\text { risk (\%) }\end{array}$ & $8.76 \pm \mid 3.91$ & $9.39 \pm 3.64$ & 0.03 & $8.72 \pm 3.3$ & $9.73 \pm 5.3$ & 0.06 & $8.33 \pm 3.43$ & $9.05 \pm 5.18$ & 0.27 \\
\hline Susceptibility score & $1.72 \pm 1.81$ & $1.81 \pm 0.91$ & 0.22 & $1.72 \pm 0.88$ & $1.92 \pm 0.95$ & 0.34 & $1.71 \pm 0.86$ & $1.85 \pm 0.98$ & 0.10 \\
\hline Severity score & $2.99 \pm 1.09$ & $1.81 \pm 0.91$ & 0.14 & $3.00 \pm 1.08$ & $2.79 \pm 1.16$ & 0.04 & $3.02 \pm 1.08$ & $2.78 \pm 1.13$ & 0.02 \\
\hline Benefit score & $3.26 \pm 1.18$ & $3.89 \pm 0.86$ & 0.001 & $3.31 \pm 1.16$ & $3.74 \pm 1.07$ & 0.001 & $3.36 \pm 1.15$ & $3.39 \pm 1.21$ & 0.80 \\
\hline Barrier score & $1.66 \pm 0.81$ & $1.47 \pm 0.60$ & 0.03 & $1.62 \pm 0.78$ & $1.65 \pm 0.81$ & 0.66 & $1.65 \pm 0.78$ & $1.55 \pm 0.79$ & 0.13 \\
\hline $\begin{array}{l}\text { Confident score/ } \\
\text { self-efficacy }\end{array}$ & $2.36 \pm 1.07$ & $3.54 \pm 0.86$ & 0.001 & $2.45 \pm 1.12$ & $3.21 \pm 1.07$ & 0.001 & $2.48 \pm 1.12$ & $2.90 \pm 1.11$ & 0.001 \\
\hline $\begin{array}{l}\text { Health motivation } \\
\text { score }\end{array}$ & $3.40 \pm 0.78$ & $3.78 \pm 0.79$ & 0.001 & $3.4 I \pm 0.78$ & $3.78 \pm 0.82$ & 0.001 & $3.44 \pm 0.77$ & $3.59 \pm 0.88$ & 0.02 \\
\hline
\end{tabular}

Notes: $F^{T}$ The value shows mean $\pm S D ;{ }^{\text {f }} \mathrm{P}$ - value from Wilcoxon rank test.

Abbreviations: BSE, breast self-examination; BCE, breast clinical examination; VAS, visual analog scale; SD, standard deviation.

mammography practice $(0.008)$. Surprisingly, the perceived severity score tended to be negatively associated with all screening performance.

\section{Discussion}

The current study showed that the perceived 5-year breast cancer risk and the lifetime risk based on subjectively 
Table 5 The Unadjusted OR of Estimate Risk and Perceived Risk and Its 95\% Confidence Interval in Performing BSE, BCE, and Mammography

\begin{tabular}{|c|c|c|c|c|c|c|}
\hline & BSE OR (95\% Cl) & p-value & BCE OR $(95 \% \mathrm{Cl})$ & p-value & Mammography OR (95\% Cl) & p-value \\
\hline Estimated 5-y risk High vs low & $0.69(0.32, I .49)$ & 0.35 & $1.56(0.82,2.98)$ & 0.17 & $2.38(I .37,4.1 I)$ & 0.002 \\
\hline Susceptibility $^{a}$ & I.II (0.9I,I.35) & 0.29 & $1.13(0.92,1.39)$ & 0.25 & I.19(0.99,I.42) & 0.06 \\
\hline Severity ${ }^{a}$ & $0.88(0.74,1.04)$ & 0.14 & $0.84(0.70,1.01)$ & 0.06 & $0.82(0.70,0.96)$ & 0.02 \\
\hline Benifit $^{a}$ & $1.72(1.42,2.07)$ & 0.001 & $1.42(1 . \mid 8, I .7 I)$ & 0.001 & $1.02(0.88,1.18)$ & 0.80 \\
\hline Barrier $^{a}$ & $0.69(0.53,0.91)$ & 0.008 & $1.06(0.83,1.35)$ & 0.62 & $0.84(0.67,1.06)$ & 0.13 \\
\hline Confidence $^{a}$ & $2.75(2.26,3.35)$ & 0.001 & $1.80(1.50,2.15)$ & 0.001 & $1.39(1.19,1.61)$ & 0.001 \\
\hline Health motoviation ${ }^{\mathrm{a}}$ & $1.89(1.48,2.43)$ & 0.001 & $1.86(|.43,2.4|)$ & 0.001 & $1.29(1.04,1.60)$ & 0.02 \\
\hline
\end{tabular}

Note: ${ }^{a} O R$ was estimated by an additional score in the likert scale using logistic regression model.

Abbreviations: BSE, breast self-examination; BCE, breast clinical examination; VAS, visual analog scale; SD, standard deviation; OR, odds ratio.

Table 6 The Adjusted OR of Estimated Risk and Perceived Risk in Performing BSE, BCE and Mammography in Multiple Logistic Regression Analysis

\begin{tabular}{|c|c|c|c|c|c|c|}
\hline $\begin{array}{l}\text { Estimated and Perceived } \\
\text { Risk }\end{array}$ & $\begin{array}{l}\text { BSE OR }{ }^{b}(95 \% \\
\text { Cl) }\end{array}$ & p-value & $\begin{array}{l}\text { BCE OR }{ }^{\mathrm{b}}(95 \% \\
\mathrm{Cl})\end{array}$ & p-value & $\begin{array}{l}\text { Mammography OR }{ }^{\mathrm{b}}(95 \% \\
\mathrm{Cl})\end{array}$ & p-value \\
\hline Estimated 5-y risk High vs low & $0.60(0.24, I .54)$ & 0.29 & $1.40(0.62,3.18)$ & 0.42 & $1.97(1.02,3.80)$ & 0.0 .04 \\
\hline Perceived Susceptibility ${ }^{a}$ & $1.20(0.95,1.49)$ & 0.13 & $1.13(0.91,1.42)$ & 0.27 & $1.31(1.07,1.59)$ & 0.008 \\
\hline Perceived severity ${ }^{\mathrm{a}}$ & $0.89(0.73,1.08)$ & 0.24 & $0.8 \mathrm{I}(0.67,0.98)$ & 0.04 & $0.86(0.73,1.25)$ & 0.10 \\
\hline Perceived benefit ${ }^{\mathrm{a}}$ & $1.14(0.91,1.43)$ & 0.25 & I.I I $(0.89,1.38)$ & 0.36 & $0.85(0.71,1.02)$ & 0.08 \\
\hline Perceived barriers ${ }^{\mathrm{a}}$ & $0.79(0.57,1.08)$ & 0.14 & $1.27(0.96,1.67)$ & 0.09 & $0.91(0.71,1.17)$ & 0.46 \\
\hline Perceived confident ${ }^{\mathrm{a}}$ & $2.60(2.04,3.31)$ & 0.001 & $1.46(1.17,1.82)$ & 0.001 & $1.33(1.10,1.62)$ & 0.003 \\
\hline Perceived health motiviation ${ }^{a}$ & $\mathrm{I} .13(0.84, \mathrm{I} .5 \mathrm{I})$ & 0.43 & $1.35(1.01,1.81)$ & 0.04 & I.II $(0.87, \mathrm{I} .42)$ & 0.39 \\
\hline
\end{tabular}

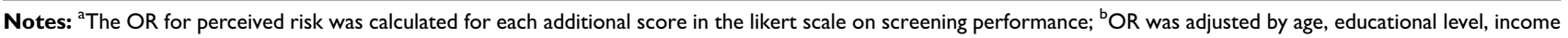
level and all subscale of perceived risk and estimated.

Abbreviations: BSE, breast self-examination; BCE, breast clinical examination; SD, standard deviation; OR, odds ratio; Cl, confidence interval.

self-report on the VAS scale are higher than the corresponded estimated risk from the Gail model. This evidence is an indicator that women of this study population perceived higher risk than an objective measure/actual risk routinely calculated by the Gail modeling approach. This pessimistic perception means that the negative event is more likely to happen to oneself than others, i.e. women tend to think they are more vulnerable and they have unrealistic pessimistic perceptions. These findings are similar to those reported by Ceber et $\mathrm{al}^{24}$ and Jones et $\mathrm{al}^{25}$ in other populations, while in contrast with Chung et al who suggested that roughly $50 \%$ of Korean women had the optimistic perception of being at risk of developing breast cancer. ${ }^{26}$ Although the knowledge of perceived risk and the risk factors of breast cancer are necessary for evaluation of breast cancer risk, ${ }^{26}$ the increased individuals' perceived risk is a trigger of anxiety and it may be an obstacle for mammography behavior. ${ }^{25}$ The higher perceived risk by women's conception in our findings may indicate the lack of sufficient knowledge of breast cancer risk factors or a higher feeling of fear concerning this tremendous disease. Albeit, the related culture in society plays an important role in individual risk perception. ${ }^{26}$

In our findings, the mean score of 5-year calculated breast cancer risk was 0.98 percent according to the Gail model that is similar to those reported from our neighborhood country among the Turkish and Iraqi women with an average 5-year risk of 0.88 and 0.95 percent respectively. ${ }^{27,28}$ Our calculated 5 -year risk by the Gail model is rather similar to other studies of Iranian women where the average 5-year risk of 0.76 percent was reported. ${ }^{29,30}$ Conversely, our estimated risk was much lower than those calculated for women in Tehran. ${ }^{19}$ In contrast to another study of Iranian women in the south part of Iran (Baluchi ethnicity), the 5-year risk was reported as 0.36 percent that is much lower than our study population. ${ }^{31}$ This lower risk of Iranian Baluchi ethnicity is probably due to the lower age at first live birth (less than 19), the higher number of the children (more than or equal to 6 children) and the higher duration of breastfeeding compared with the ethnic group of our study population. Meanwhile, several studies reported that reproductive factors play a key role in decreasing breast cancer risk. ${ }^{32,33}$ 
The published data shows that the risk of developing breast cancer varied according to ethnicity and sociodemographic characteristics, and lifestyles and reproductive behaviors. ${ }^{20,34}$ In our results, roughly $1.8 \%$ of women had a lifetime risk of more than $20 \%$. However, a study in the United States showed that about $1.09 \%$ of American women aged 30 to 84 , had a lifetime risk of more than $20 \%$ accounted to nearly 900,000 US women are eligible for MRI breast screening. ${ }^{34}$ The higher proportion of women with a lifetime risk of more than $20 \%$ in our study compared with the US population may be explained by the higher lower bond of age included in this study ( 35 versus 30 years).

Based on our findings, the calculated 5-year risk was a significant predictor of mammography practice but not for BSE and BCE practices, since these two later screening behaviors are not necessarily the individual women to be at high risk. Also, the findings showed that perceived selfefficacy remained significant after being adjusted by other subscales of HBM, calculated risk and demographic characteristics with all three screening procedures. Our results indicated that women with regular performance of BSE compared with those without regular BSE performance tended to have a higher perceived susceptibility, perceived benefit, self-efficacy, health motivation, and the lower barriers and perceived severity. In contrast to our previous reports ${ }^{13,14}$ and other similar studies, the perceived severity, perceived benefits, self-efficacy and health motivation had a positive significant association with breast cancer screening behaviors. ${ }^{7,35,36}$

In this study, women who performed mammography routinely had a higher 5-year risk score and also lifetime risk score compared with those who did not perform it. These results are in line with other findings. ${ }^{37}$ An interesting finding was that this effect remained significant after adjusting the perceived risk of all subscales of HBM and demographic characteristics as well, while some component of the health belief model was not significant by adjusting the calculated risk. This implies that the Gail model of risk assessment and its cut-off criteria should be considered as an objective measure of undergoing mammography. One might argue that women with a high risk (based on the Gail model) did not know about being at higher risk before breast examination (BSE, BCE, and mammography). Thus, how the calculated risk in the Gail model is a clinical indicator of undergoing mammography independent from the health belief scale in Iranian women. However, the awareness of women and their clinician regarding the presence of breast cancer risk that may contribute as an indicator of breast examination, especially mammography. The apparent association is explained for some reasons. Many researchers reported that the major causes of undergoing mammography are a family history of breast cancer, the presence of a benign mass in the breast and physician recommendation due to some other symptoms and signs of breast problems. ${ }^{38}$ Although some aspects of mammography might be at debates, the evidence support that adherence to mammography screening and its widespread implementation reduced the death from breast cancer for women aged $50-75$ years by $20 \%$ to $25 \%$ during the past four decades. ${ }^{39}$ A recent study showed that the organized mammography screening had a lower proportion of metastatic lymph nodes, lower rate breast-conservative surgery, and less tumor size and to have a shorter hospital stay in women aged 50 to 69 years. ${ }^{39}$

The Gail risk assessment model used in this study may have limitations. It may underestimate the risk of developing breast cancer since it does not take into account racial or ethnic variation, BRCA genetic variants, tamoxifen use, and excludes women with ductal and lobular breast carcinoma in situ. Also, it may not apply to young women not undergoing regular mammography, particularly women aged 35 to 39 recruited in this study. However, this model is a flexible tool for primary screening in population-level and individual risk assessment among women with no history of diagnosis of invasive and noninvasive breast carcinoma. Another limitation of our study was that a few participants (about 10\%) may not have been in the mood to write/or interview. Some individuals may not have consent. We expected such nonresponse is non-differentiate concerning their risk score. This may happen in either group under comparison. Thus, the bias would be canceled out.

The Gail model has been validated in breast cancer risk prediction in different populations and it is generally accurate in risk projection. ${ }^{25-28}$ However, some overestimation of the likelihood of risk may occur in a specific subgroup (e.g. younger women who are not a candidate of regular mammography) and its baseline risk was taken into account from age-specific breast cancer incidence of US women. According to the latest national cancer database in Iran, the age-standardized incidence rate of breast cancer was 33.21 per 100,000 women per year. ${ }^{40}$ However, the calculated lifetime risk in our study and other similar studies in Iranian women is higher than that is interpolated from the reported annual incidence rate. It is possible that 
the reported annual incidence rate to be underestimated since the lack of sufficient monitoring in reporting of all new cases. Nevertheless, it is required to build a risk assessment model in Iranian women with and without a history of ductal or lobular breast carcinoma in situ and BRCA1 and BRCA2. Also, further investigation in model selection in breast cancer risk assessment in Iranian women should focus beyond the risk factors considered in the Gail model. The other lifestyle risk factors add new insight into the risk assessment model. Besides, the excess perceived risk in the current study as compared with the actual risk might be a measure of indicator to correct the trend of subjective risk assessment in breast cancer. Appropriate educational programs are recommended to focus on benefits of BSE and mammography in early detection of breast cancer. Such programs would also create positive motivation for women and increase their adherence toward the action and maintenance stages. This also would ameliorate the level of perception of breast cancer development and the knowledge of breast cancer prevention/diagnosis in Iranian women.

\section{Conclusion}

The estimated 5-year risk and lifetime risk of developing women breast cancer in Iranian women are comparable to western countries. The findings imply that the perceived risk from HBM scale was meaningful in screening attendance. In particular, self-efficacy was the most decisive factor across all three screening methods while the calculated risk from the Gail model is a clinical indicator of undergoing mammography independently from HBM scales in Iranian women but not for BSE and BCE. Because of the increasing trend of breast cancer in Iranian women, the risk assessment should be implemented in clinical practice as a primary tool to select the eligible women for mammography screening programs.

\section{Abbreviations}

HBM, health belief model; BSE, breast self-examination; BCE, breast clinical examination; NIMAD, National Institute of Medical Research Development; OR, odds ratio.

\section{Ethics Statement}

This study was conducted in accordance with the Declaration of Helsinki and it was approved by the Ethics Committee of the National Institute for Medical Research Development (NIMAD), Tehran, Iran. Informed consent was obtained from all patients prior their participation in the study.

\section{Acknowledgments}

We would like to extend our sincere gratitude to the National Institute for Medical Research Development (NIMAD), Tehran, Iran. Additionally, we would like to give many thanks to our students, and nurses who assisted in data collection. The research reported in this publication was supported by the Elite Researcher Grant Committee under the award number [958741] from the National Institute for Medical Research Development (NIMAD), Tehran, Iran.

\section{Author Contributions}

All authors made substantial contributions to conception and design, acquisition of data, or analysis and interpretation of data; took part in drafting the article or revising it critically for important intellectual content; gave final approval of the version to be published; and agree to be accountable for all aspects of the work.

\section{Disclosure}

The authors report no conflicts of interest in this work.

\section{References}

1. WHO. Introduction of breast cancer; 2016. Available from: http:/ WWW.who.int/cancer/detection/breastcancer/en/.

2. Ferlay J, Soerjomataram I, Ervik M, et al. Cancer Incidence and Mortality Worldwide: IARC Cancer Base No. 11. Lyon, France: International Agency for Research on Cancer;2013. Available from http://globocan.iarc.fr.

3. American Cancer Society, Breast Cancer, Facts \& Figures 2015-2016, Atlanta, American cancer Society, Inc; 2015. Available from: https://www.cancer.org/content/dam/cancer-org/research/can cer-facts-and-statistics/breast-cancer-facts-and-figures/breast-cancerfacts-and-figures-2015-2016.pdf.

4. Hajian-Tilaki KO, Ahangar T. Reproductive factors associated with breast cancer risk in northern Iran. Med Oncol. 2011;28(2):441-446. doi:10.1007/s12032-010-9498-z

5. Mousavi SM, Gouya MM, Ramazani R, Davanlou M, Hajsadeghi N, Seddighi Z. Cancer incidence and mortality in Iran. Ann Oncol. 2009;20:556-563. doi:10.1093/annonc/mdn642

6. Taghavi IA, Fazeli Z, Vahedi M, et al. Increased trend of breast cancer mortality in Iran. Asian Pac $J$ Cancer Prev. 2012;13:367-370. doi:10.7314/APJCP.2012.13.1.367

7. Parsa P, Kandiah M, Moha Nasir MT, Hejar AR, Afiah MZ. Reliability and validity of Champion's health belief model scale for breast cancer screening among Malaysian women. Singap Med J. 2008;49:897-903.

8. Secginli S, Nahcivan NO. Reliability and validity of the breast cancer screening belief scale among Turkish women. Cancer Nurs. 2004;27 (4):287-294. doi:10.1097/00002820-200407000-00005

9. Breast cancer risk prediction models NCI website. Available from: $\mathrm{http} ; / /$ riskfactor.cancer.gov/cancerriskprediction/breast.html.

10. Gail MH, Brinton LA, Byar DP, et al. Projecting individualized probabilities of developing breast cancer for white females who are being examined annually. J Natl Cancer Inst. 1989;181:1879-1886. doi:10.1093/jnci/81.24.1879 
11. Delavar MA, Hajian-Tilaki KO. Age at menarche in girls born from 1985 to 1989 in Mazandaran, Islamic Republic of Iran. East Mediterr Health J. 2008;14(1):90-94.

12. Hajian-Tilaki KO, Heidari B. Prevalence of obesity, central obesity and the associated factors in urban population aged 20-70 years, in the north of Iran: a population-based study and regression approach. Obes Rev. 2007;8(1):3-10. doi:10.1111/j.1467-789X.2006.00235.x

13. HajianTilaki K, Auladi S. Awareness, attitude and practice of breast cancer screening women, and the associated socio-demographic characteristics, in northern Iran. Iran J Cancer Prev. 2015;8(4):e3429. doi:10.17795/ijcp-3991

14. Hajian-Tilaki K, Auladi S. Health belief model and practice of breast self-examination and breast cancer screening in Iranian women. Breast Cancer. 2012;2014(21):429-434.

15. Hajian-Tilaki K, Heidari B, Firouzjahi A, Bagherzadeh M, HajianTilaki A, Halalkhor S. Prevalence of metabolic syndrome and the association with socio-demographic characteristics and physical activity in urban population of Iranian adults: a population-based study. Diabetes MetabSyndr. 2014;8(3):170-176.

16. Khazaee M, Majlessi F, Nedjat S, Montazeri A, Janani I, Pashaei T. Assessing breast cancer risk among Iranian women using the Gail model. Asian Pac J Cancer Prev. 2016;1798:3759-3762.

17. Seyednoori T, Pakseresht S, Roushan Z. Risk of developing breast cancer by utilizing Gail model. Women Health. 2012;52(4):391-402. doi:10.1080/03630242.2012.678476

18. Mirghafourvand M, Mohammad-Alizadeh-Charandabi S, Ahmadpour P, Rahi P. Breast cancer risk based on the Gail model and its predictors in Iranian women. Asian Pac J Cancer Prev. 2016;17(8):3741-3745.

19. Mohammadbeigi A, Mohammadsalehi N, Valizadeh R, Momtaherni Z, Mokhtari M, Ansari H. Lifetime and 5-year risk of breast cancer and attributable risk factor according to Gail model in Iranian women. J Pharm Biollied Sci. 2015;7(3):207-211. doi:10.4103/0975-7406.160020

20. Sakorafas GH, Krespis E, Pavlakis G. Risk assessment for breast cancer development: a clinical prospective. Surg Oncol. 2002;10:183-192. doi:10.1016/S0960-7404(02)00016-6

21. Rockhill B, Spiegelman D, Byrne C, Hunter DJ, Colditz GA. Validation of the Gail et al. Model of breast cancer risk prediction and implications for chemoprevention. J Natl Cancer Inst. 2001;93 (5):358-366. doi:10.1093/jnci/93.5.358

22. Costantino JP, Gail MH, Pee D, et al. Validation studies for model projecting the risk of invasive and total breast cancer incidence. J Natl Cancer Inst. 1999;91:1541-1548. doi:10.1093/jnci/91.18.1541

23. Chay WY, Ong WS, Tan PH, et al. Validation of the Gail model for predicting individual breast cancer risk in a prospective nationwide study of 28,104 Singapore women. Breast Cancer Res. 2012;14:R19. doi:10.1186/bcr3104

24. Çeber E, Soyer MT, Ciçeklioglu M, Cimat S. Breast cancer risk assessment and risk perception on nurses and midwives in Bornova Health District in Turkey. Cancer Nurs. 2006;29(3):244-249. doi:10.1097/00002820-200605000-00013

25. Jones SC, Magee CA, Barrie LR, et al. Australian women's perceptions of breast cancer risk factors ant the risk of developing breast cancer. Women's Health Issues. 2011;21(5):353-360. doi:10.1016/j. whi.2011.02.004
26. Chung CW, Lee SJ. Estimated risks and optimistic self-perception of breast cancer risk in Korean women. Appl Nurs Res. 2013;26 (4):180-185. doi:10.1016/j.apnr.2013.06.001

27. Ebril N, Dundar N, Inan C, Bolukbas N. Breast cancer risk assessment using the Gail model: a Turkish study. Asian Pac J Cancer Prev. 2015;16(1):303-306. doi:10.7314/APJCP.2015.16.1.303

28. Ewaid SH, Al-Azzawi LHA. Breast cancer risk assessment by Gail model in women of Baghdad. Alexandria J Med. 2017;53:183-186. doi:10.1016/j.ajme.2016.09.001

29. Omranipour R, Karbakhsh M, Behforouz A, et al. Performance of the Gail model for breast cancer risk assessment in Iranian women. Arch Breast Cancer. 2015;2(1):27-31.

30. Behboudi F, Ashoorizadeh B. Gail model to determine the risk of breast cancer. J Guilan Univ Med Sci. 2014;22(88):7-11.

31. Ansari H, Mohammadi M, Mohammadi Y, et al. Assessment of socio-economic and menstrual-reproductive factors related to estimated risk of affecting to breast cancer in the Iranian woman. Koomesh. 2018;20(3):439-446.

32. Sweeney C, Baumgartner KB, Byers T, et al. Reproductive history in relation to breast cancer risk among Hispanic and non-Hispanic white women. Cancer Causes Control. 2008;19:391-401. doi:10.1007/ s10552-007-9098-1

33. Shantakumar S, Terry MB, Teitelbaum SL, et al. Reproductive factors and breast cancer risk among older women. Breast Cancer Res Treat. 2007;102:365-374. doi:10.1007/s10549-006-9343-4

34. Graubard BI, Freedman AN, Gail MH. Five-year lifetime risk of breast cancer among U.S. sub population: implications for magnetic resonance imaging. Cancer Epidemiol Biomarkers Prev. 2010;19 (1):2430-2436. doi:10.1158/1055-9965.EPI-10-0324

35. Secginli S, Nahcivan NO. Factors associated with breast cancer screening behaviors in a sample of Turkish women: a questionnaire survey. Int J Nurs Stud. 2006;43(2):161-171. doi:10.1016/j.ijnurstu. 2005.02.004

36. Fouladi N, Amani F, Sadeghi F, et al. Related factors in women following breast cancer surgery. Middle East J Cancer. 2016;7 (1):41-45.

37. Baysal HY, Polat H. Determination of breast cancer risk levels and health belief of women with and without previous mammography in eastern part of Turkey. Asian Pac J Cancer Prev. 2012;13 (10):5213-5217. doi:10.7314/APJCP.2012.13.10.5213

38. Elobaid YE, Aw TC, Grivna M, Nagelkerke N. Breast cancer screening awareness, knowledge, and practice among Arab women in the United Arab Emirates: a cross-sectional survey. PLoS One. 2014;9 (9):1-7. doi:10.1371/journal.pone.0105783

39. Fancellu A, Sanna V, Sedda M, et al. Benefits of organized mammography screening programs in women aged 50 to 69 years: a surgical perspective. Clin Breast Cancer. 2019;19(5):e637-e642. doi:10.1016/ j.clbc.2019.04.013

40. Nafissi N, Khayamzadeh M, Zeinali Z, Pazooki D, Hosseini M, Akbari ME. Epidemiology and histopathology of breast cancer in iran versus other middle eastern countries. Middle East J Cancer. 2018;9(3):243-251.
Cancer Management and Research is an international, peer-reviewed open access journal focusing on cancer research and the optimal use of preventative and integrated treatment interventions to achieve improved outcomes, enhanced survival and quality of life for the cancer patient.
The manuscript management system is completely online and includes a very quick and fair peer-review system, which is all easy to use. Visit http://www.dovepress.com/testimonials.php to read real quotes from published authors. 